\title{
Manual de los Reglamentos del Agua en Florida: Departamento de Protección Ambiental en Florida ${ }^{1}$
}

\author{
Michael T. Olexa, Luke D'Isernia, Laura Minton, Dulcy Miller y Sara Corbett ${ }^{2}$
}

\section{Prefacio}

Este manual esta diseñado para proporcionar un resúmen autorizado, exacto y actual de las principales leyes Federales y de Florida que están directa o indirectamente relacionadas a la agricultura. Este manual debe proveer una vista general de los muchos derechos y responsabilidades que tienen los agricultores y propietarios de tierras agrícolas bajo las leyes tanto Federal como de Florida, así como también la información de los contactos apropiados para obtenerla con más detalle. Sin embargo, el lector debe estar advertido de que algunas partes de esta publicación podrían volverse obsoletas en cualquier momento, debido a que las leyes, reglas administrativas, y decisiones de la corte, sobre las cuales se basa este manual, se encuentran bajo revisión constante. Algunos detalles de las leyes citadas no se mencionan, debido a limitaciones de espacio.

Este manual es distribuido con la aclaración de que los autores no intentan proporcionar una asesoría legal o profesional, y que la información contenida aquí no debe ser considerada como un sustituto de asesoría profesional. En este manual, no se incluye toda la información para llevar a cabo el cumplimiento de las leyes Federales y de Florida y los reglamentos que rigen la protección del agua. Por estas razones, el uso de estos materiales por cualquier persona, constituyen un acuerdo para mantener libre de perjuicios a los autores, al Servicio de Extensión Cooperativa de Florida, al Instituto de los Alimentos y Ciencias Agrícolas y a la Universidad de Florida por reclamos de responsabilidad, daños o gastos provenientes de quien sea, por haberse referido o basado en la información contenida en este manual.

\section{Vista General}

El Departamento de Protección Ambiental (DPA) fue creado por la Ley de Reorganización Ambiental de Florida de 1993. Su responsabilidad primaria es preservar la integridad del medio ambiente físico de Florida, especialmente aire y el

1. Este es el documento EDIS FE076, una publicación de Food and Resource Economics Department, Florida Cooperative Extension Service, Institute of Food and Agricultural Sciences, University of Florida, Gainesville, FL. Publicado Noviembre 2006. Por favor visite la página electrónica de EDIS en http://edis.ifas.ufl.edu.

2. Michael T. Olexa, profesor, Food and Resource Economics Department y director, Agricultural Law Center, University of Florida, Gainesville, FL, y presidente, Agricultural Law Committee, The Florida Bar; Luke D'Isernia, alumni, Levin College of Law, University of Florida, Gainesville, FL; Laura Minton, abogado, Dean, Mead, Egerton, Bloodworth, Capouano y Bozarth, PA, Orlando FL; Dulcy Miller, abogado, Foley and Lardner, LLP, Orlando, FL; y Sarah Corbett, abogado, Florida Second District Court of Appeal, Lakeland, FL. La traducción del ingles al español estuvo a cargo de Filiberto Reyes-Villanueva. 
agua. Además esto incluye un gran numero de obligaciones, solamente serán discutidas aquellas obligaciones relevantes al alcance de este manual. Estas incluyen las siguientes:

- Los permisos de drenado y relleno en aguas del estado.

- La Ley de Administración de los Recursos Acuáticos de 1972, Capitulo 373 de los Estatutos de Florida.

- Revisión de los distritos de control del agua.

- Regulación de la contaminación del aire, agua y ruido.

- Manejo de desechos sólidos y peligrosos.

- Abastecimiento de agua potable.

- Control de hierbas acuáticas nocivas.

- Regulación de pozos de inyección y pozos relacionados con la exploración de petróleo.

- La prevención o limpieza de contaminación de derrames o descargas dentro de las aguas o tierras del estado.

- Administración de las leyes federales tales como la Ley del Agua Limpia y la Ley del Agua Potable Segura de Florida.

\section{¿Con Quién Comparte Poderes el DPA?}

El DPA ha delegado específicamente el poder del manejo del agua de los distritos para administrar y hacer cumplirlas disposiciones del Capitulo 373, de los Estatutos de Florida, también conocidos como la Ley de los Recursos Acuáticos de Florida de 1972. El DPA también otorga autoridad al Departamento de Agricultura y Servicios al Consumidor (DASC), el cual regula ciertas actividades de quemas abiertas a través de la División Forestal.

\section{¿Cómo Esta Estructurado el DPA?}

El DPA esta dividido en diecisiete divisiones y la Oficina de la Secretaria. De esas, las cinco más importantes son:
1. Servicios Administrativos provee servicios de ayuda para el DPA, lo que incluye personal, contabilidad y compra. Los Servicios

Administrativos contienen cuatro oficinas: Servicios de Personal, Finanzas y Contabilidad, Presupuesto y Planificación, y Servicios Generales.

2. Manejo de Recursos del Aire implementa la Ley del Aire Limpio y los Estatutos apropiados de Florida; monitorea la calidad del aire del estado, administra los programas de control de la contaminación del aire del estado; emite permisos para las fuentes de contaminación del aire; y coordina los esfuerzos con otros programas locales, estatales y federales de calidad del aire.

3. Manejo de los Recursos Acuáticos supervisa los programas para ayudar a proveer el agua pura segura para tomar, recuperar las tierras después que han estado minadas por fosfato y otros materiales, e implementa programas para protección del agua del suelo a través de permisos, cumplimiento y aplicación.

4. Manejo de Desecho es responsable por el manejo de desechos sólidos y peligrosos, incluyendo la limpieza de desechos peligrosos y sitios contaminados por derrames. El Manejo de Desechos contiene tres oficinas: la Oficina de Sistemas de Almacenamiento de Petróleo, la cual supervisa el estado en que se encuentran los tanques superficiales y subterráneos de almacenamiento de contaminantes y el programa de limpieza del petróleo; la Oficina de Desecho Sólido y Peligroso, es responsable de planificar, manejar, dar permisos y regular desechos sólidos y peligrosos y; la Oficina de Limpieza de Desechos, la cual es responsable por todas las actividades relacionadas a los sitios de la limpieza y para conducir investigaciones de contaminación del agua superficial. También dispone de asistencia científica e ingeniería técnica y revisa los programas de la División de limpieza de no petróleo, y dirige el Foro de Suelos Contaminados, créditos de impuestos para limpieza voluntaria, y mantiene el Registro de Control Institucional (http://gisweb.dep.state.fl.us/dwn/icr) para los 
sitios contaminados.

\section{División de Permisos de los Recursos}

Ambientales esta a cargo de los programas de protección de recursos y pantanos, incluyendo la Oficina del Manejo de Plantas Acuáticas la cual regula el control de las plantas acuáticas nocivas.

Las oficinas de los distritos del DPA contienen su propia estructura, la cual es usualmente similar a la oficina central de Tallahassee. Colectivamente, los distritos son responsables por la política, planificación y actividades de reglamentación. Cada distrito esta encabezado por un Director del Manejo de Distrito. Las responsabilidades para permisos, monitoreo del cumplimiento y la aplicación de las actividades de vigilancia están divididas entre las oficinas centrales y de distrito, aunque los distritos hacen la mayoría del trabajo en esas áreas.

\section{Agradecimientos}

Los autores agradecen al personal de las agencias estatales y federales por su tiempo y asesoría en la preparación de este manual. Los autores agradecen especialmente a Richard Budell del Office of Agricultural Water Policy of the Florida Department of Agriculture and Consumer Services por el apoyo económico para el desarrollo de esta publicación. 